Artikel Penelitian

\title{
Optimasi Formula Sediaan Lotion Ekstrak Daun Jambu Biji (Psidium guajava L.) Dengan Variasi Konsentrasi Setil Alkohol Dan Gliserin
}

\author{
Lotion Formula Optimization Of Extract Guava Leave (Psidium \\ guajava L.) With Variation Of Cetyl Alcohol And Glycerin \\ Concentration
}

\author{
Hardiyanti Dewi Azmi, Windah Anugrah Subaidah*, Yohanes \\ Juliantoni \\ Laboratorium Formulasi dan Teknologi Sediaan, Jurusan Farmasi, Fakultas \\ Kedokteran, Universitas Mataram, J1 Majapahit No. 62, Mataram 83125, Indonesia \\ *E-mail: windahanugrah@unram.ac.id
}

\begin{abstract}
Abstrak
Daun jambu biji (Psidium guajava L.) mengandung senyawa flavonoid yang berpotensi sebagai antioksidan yang dapat mencegah terjadinya kerusakan kulit karena radikal bebas sehingga produk kosmetik sediaan topikal dengan zat aktif ekstrak daun jambu biji perlu dikembangkan. Tujuan dilakukannya penelitian ini untuk menentukan formula optimum sediaan lotion ekstrak daun jambu biji (Psidium guajava L.) dengan variasi setil alkohol dan gliserin serta menentukan sifat fisik formula optimumnya. Metode ekstraksi yang digunakan yaitu maserasi dengan pelarut etanol $96 \%$. Nilai rendemen yang diperoleh yaitu $17,64 \%$. Hasil skrining flavonoid menunjukkan hasil positif yang ditandai dengan terjadinya perubahan warna larutan menjadi merah. Optimasi formula dilakukan dengan metode Simplex Lattice Design yang diolah menggunakan software Design Expert dan sediaan lotion diformulasi dengan meleburkan bahan fase minyak (asam stearat, setil alkohol, propil paraben) dan fase air (trietanolamin, gliserin, metil paraben, akuades) secara terpisah pada suhu $70-75^{\circ} \mathrm{C}$, kemudian disatukan dan diaduk hingga homogen. Hasil optimasi menunjukkan formula optimum lotion diperoleh pada konsentrasi setil alkohol dan gliserin masing-masing sebesar 3,93\% dan $13,07 \%$. Hasil evaluasi sifat fisik formula optimum yaitu memilki warna hijau kecoklatan, bau khas daun jambu biji, konsistensi yang kental dan $\mathrm{pH} 7,942$, daya sebar $6,350 \mathrm{~cm}$ dan daya lekat 0,975 detik.

Kata kunci: daun jambu biji, lotion, simplex lattice design.
\end{abstract}




\begin{abstract}
Guava leaves (Psidium guajava L.) contain flavonoid compounds that have an antioxidants effect. It can prevent skin damage due to free radical molecules. Therefore, topical cosmetic products with an active ingredient of guava leaf extract need to be developed. The purpose of this study was to determine the optimum formula for guava leaf extract lotion (Psidium guajava L.) (variation of cetyl alcohol and glycerin) and to determine the physical properties of the optimum formula. The maceration extraction method with $96 \%$ ethanol as solvent which obtained $17,64 \%$ of rendemen value. Screening test of flavonoid was showed positive result by the color of the solution changed into red. The formula was optimized by using the Simplex Lattice Design method and processed by using Design Expert software. The lotion preparation was prepared by melting the oil phase (stearic acid, cetyl alcohol, propyl paraben) and water phase (triethanolamine, glycerin, methyl paraben, aquadest) separately at $70-75^{\circ} \mathrm{C}$ then put it together and stirred until homogeneous. The result was showed that the optimum formula was obtained with concentrations of cetyl alcohol and glycerin of $3.93 \%$ and $13.07 \%$, respectively. The evaluation physical properties of the optimum formula were a brownish-green color lotion with a distinctive odor of guava leaves, a thick consistency, $\mathrm{pH}$ value 7,942 , spreadability value $6,350 \mathrm{~cm}$, and adhesion value 0,975 seconds.
\end{abstract}

Keywords: guava leaves, lotion, simplex lattice design.

\title{
PENDAHULUAN
}

Radikal bebas dapat berasal dari sinar ultraviolet yang dapat menyebabkan terjadinya proliferasi sel secara terus menerus sehingga menjadi awal terbentuknya kanker kulit (Sari, 2015). Masalah ini dapat dicegah dengan memberikan perlindungan terhadap kulit. Salah satunya dengan menggunakan kosmetik yang mengandung antioksidan.

Antioksidan alami dapat diperoleh dari beberapa jenis tumbuhan (Alissya et al., 2013), salah satunya yaitu daun jambu biji (Psidium guajava L.). Hasil penelitian Vyas et al. (2010) juga membuktikan bahwa daun jambu biji memiliki aktivitas antioksidan dengan nilai $\mathrm{IC}_{50}$ sebesar $45 \mu \mathrm{g} / \mathrm{mL}$ yang dapat dikategorikan sebagai antioksidan kuat. Oleh karena itu perlu dilakukan pengembangan produk kosmetik dalam bentuk sediaan lotion dengan zat aktif ekstrak daun jambu biji. Sediaan lotion ini dipilih karena mudah diaplikasikan, daya penyebaran dan penetrasinya cukup tinggi, tidak memberikan rasa berminyak, memberikan efek sejuk, serta mudah dicuci dengan air (Aulton, 2007).

Dalam memformulasikan sediaan lotion perlu diperhatikan bahan yang menjadi basis sediaan seperti penstabil dan humektan yang akan mempengaruhi sifat fisik dari sediaan. Setil alkohol berfungsi sebagai penstabil yang dapat meningkatkan stabilitas dari emulsi tipe minyak dalam air (M/A) (Rowe et al., 2009) dan memberikan sifat semi padat, sedangkan gliserin berfungsi sebagai humektan digunakan untuk mengontrol kadar air dalam sediaan (Hendradi et al., 2013) sehingga perlu dilakukan optimasi formula sediaan lotion dengan variasi konsentrasi setil alkohol dan gliserin yang diperkirakan dapat 
mempengaruhi sifat fisik ( $\mathrm{pH}$, daya sebar, daya lekat) sediaan. Metode optimasi yang digunakan yaitu Simplex Lattice Design. Adapun tujuan dilakukannya penelitian ini adalah untuk menentukan formula optimum sediaan lotion ekstrak daun jambu biji (Psidium guajava L.) dengan variasi setil alkohol dan gliserin serta mengetahui sifat fisik formula optimum yang diperoleh.

\section{BAHAN DAN METODE}

\section{Pembuatan simplisia}

Daun jambu biji (Psidium guajava L.) sebanyak $1 \mathrm{~kg}$ diambil di Kota Praya Kabupaten Lombok Tengah. Daun jambu biji disortasi basah dan dibersihkan dengan air bersih. Daun jambu biji dirajang kemudian dikeringkan di bawah cahaya matahari dengan ditutupi kain hitam. Daun jambu biji yang telah kering disortasi kering kemudian diblender dan disimpan di dalam wadah.

\section{Ekstraksi sampel}

Serbuk simplisia daun jambu biji diekstraksi dengan metode maserasi menggunakan pelarut etanol 96\% (Merck). Serbuk simplisia 500 gram dimasukkan ke dalam bejana maserasi dan ditambahkan pelarut etanol 96\% sebanyak $3500 \mathrm{ml}$ dengan perbandingan 1:7. Perendaman ini dilakukan selama 3 kali 24 jam dengan 2 kali remaserasi dan dilakukan pengadukan. Kemudian ekstrak dipekatkan dengan rotary evaporator (Hahn Shin) pada suhu 40-50oC hingga terbentuk ekstrak kental.

\section{Skrining fitokimia flavonoid}

Skrining fitokimia ekstrak daun jambu biji dalam penelitian ini dilakukan uji flavonoid. Sebanyak 0,1 g sampel dimasukkan ke dalam gelas kimia dan ditambah dengan $10 \mathrm{ml}$ etanol (Merck) dan dipanaskan selama 5 menit, kemudian ditambahkan 10 tetes $\mathrm{HCl}$ pekat (Merck) dan 0,2 g serbuk Mg (Merck).

\section{Pembuatan sediaan lotion}

Pembuatan sediaan lotion ekstrak daun jambu biji dengan metode peleburan dengan formula seperti yang tercantum pada tabel 1. Fase minyak yang terdiri dari asam stearate (Zhengzhou Sino Chemical), setil alcohol (Echo chem), dan propil paraben (Shijiazhuang Jinghong Chemical Technology) dileburkan di atas hot plate (Accuplate ${ }^{\mathrm{TM}}$ ) pada suhu $70-75^{\circ} \mathrm{C}$. Fase air yang terdiri dari trietanolamin (Henan Tianfu Chemcal), gliserin (Guangzhou Zio Chemical), metil paraben (Hefei TNJ Chemical) dan aquades dileburkan dengan langkah yang sama seperti fase minyak secara terpisah. Selanjutnya fase minyak ditambahkan ke dalam fase air secara perlahan sambil diaduk sampai kedua fase tersebut homogen, kemudian ditambahkan ekstrak daun jambu biji dan dilakukan pengadukan hingga terbentuk sediaan lotion. 


\section{Evaluasi sifat fisik sediaan}

Evaluasi sifat fisik sediaan lotion pada penelitian ini terdiri dari uji organoleptis, uji pH (Ohaus starter 300), uji daya sebar, dan uji daya lekat.

Tabel 1. Formula Sediaan Lotion dengan Variasi Konsentrasi Setil Alkohol dan Gliserin (Rowe et al., 2009; Mulyani et al., 2018)

\begin{tabular}{cccccccccc}
\hline Bahan & \multicolumn{8}{c}{ Formula (\% b/v) } & Fungsi \\
\cline { 2 - 9 } & F1 & F2 & F3 & F4 & F5 & F6 & F7 & F8 & \\
\hline Ekstrak daun & 2 & 2 & 2 & 2 & 2 & 2 & 2 & 2 & Zat aktif \\
jambu biji & & & & & & & & & \\
Asam stearat & 2,5 & 2,5 & 2,5 & 2,5 & 2,5 & 2,5 & 2,5 & 2,5 & Emulgator \\
Trietanolamin & 2 & 2 & 2 & 2 & 2 & 2 & 2 & 2 & Emulgator \\
Setil alkohol & 2 & 2,75 & 3,5 & 5 & 4,25 & 5 & 2 & 3,5 & Penstabil \\
Gliserin & 15 & 14,25 & 13,5 & 12 & 12,75 & 12 & 15 & 13,5 & Humektan \\
Propil paraben & 0,1 & 0,1 & 0,1 & 0,1 & 0,1 & 0,1 & 0,1 & 0,1 & Pengawet \\
Metil paraben & 0,1 & 0,1 & 0,1 & 0,1 & 0,1 & 0,1 & 0,1 & 0,1 & Pengawet \\
Akuades & ad & ad & ad & ad & ad & ad & ad & ad & Pelarut \\
& 100 & 100 & 100 & 100 & 100 & 100 & 100 & 100 & \\
\hline
\end{tabular}

\section{Analisis statistic}

Analisis data statistik dalam penelitian ini menggunakan software Design Expert versi 11 untuk menentukan formula sediaan lotion ekstrak daun jambu biji yang optimum. Verifikasi data hasil percobaan dan prediksi kemudian diuji secara statistik menggunakan t-test. Nilai $\mathrm{p}<0,05$ menunjukkan adanya perbedaan data yang signifikan.

\section{HASIL}

\section{Pembuatan simplisia}

Sebanyak $1 \mathrm{~kg}$ daun jambu biji yang telah disortasi basah kemudian dibersihkan dan dirajang kasar. Daun jambu biji kemudian dikeringkan. Daun jambu biji yang telah kering kemudian diserbukkan dengan blender sehingga diperoleh simplisia kering sebanyak 526,17 gram.

\section{Ekstraksi sampel}

Ekstrak kental daun jambu biji yang diperoleh sebanyak 88,18 gram, berwarna hijau pekat kehitaman, memiliki bau khas daun jambu biji dan memiliki konsistensi yang kental. Rendemen yang diperoleh sebesar $17,64 \%$.

\section{Skrining flavonoid}

Hasil skrining fitokimia yang diperoleh dari penelitian ini menunjukkan adanya senyawa flavonoid pada ekstrak daun jambu biji yang ditandai dengan terjadinya perubahan warna larutan menjadi merah. 


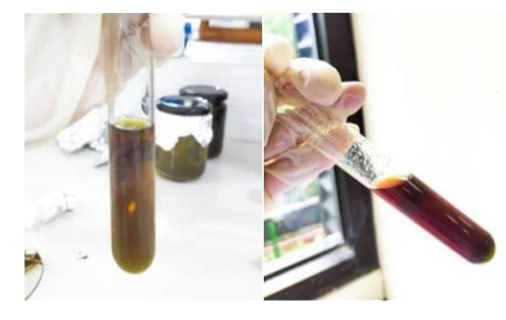

(a)

(b)

Gambar 2. Hasil skrining flavonoid (a) sebelum ditambahkan MG, 9b) setelah ditambahkan $\mathrm{Mg}$

\section{Optimasi Formula Sediaan Lotion Ekstrak Daun Jambu Biji}

Tabel 2. Nilai Respon Setiap Run Formula dari Ketiga Parameter.

\begin{tabular}{cccc}
\hline & \multicolumn{3}{c}{ Respon } \\
\cline { 2 - 4 } Run & $\mathbf{p H}$ & $\begin{array}{c}\text { Daya Sebar } \\
(\mathbf{c m})\end{array}$ & $\begin{array}{c}\text { Daya Lekat } \\
\text { (detik) }\end{array}$ \\
\hline 1 & 7,74 & 8 & 0,87 \\
2 & 7,76 & 6,95 & 1,95 \\
3 & 7,82 & 6,5 & 2,5 \\
4 & 8,07 & 6,6 & 0,88 \\
5 & 8,01 & 7,45 & 1,29 \\
6 & 8,03 & 6,55 & 0,84 \\
7 & 7,81 & 8,65 & 0,8 \\
8 & 7,80 & 6,25 & 1,9 \\
\hline
\end{tabular}

Tabel 3. Persamaan SLD masing-masing respon

\begin{tabular}{cc}
\hline Respon & Persamaan \\
\hline $\mathrm{pH}$ & $\mathrm{Y}=8,07(\mathrm{~A})+7,77(\mathrm{~B})-0,3325(\mathrm{~A})(\mathrm{B})$ \\
\hline Daya sebar & $\mathrm{Y}=6,77(\mathrm{~A})+8,22(\mathrm{~B})-3,43(\mathrm{~A})(\mathrm{B})$ \\
\hline Daya lekat & $\mathrm{Y}=0,7663(\mathrm{~A})+0,8908(\mathrm{~B})+5,03(\mathrm{~A})(\mathrm{B})$ \\
\hline
\end{tabular}



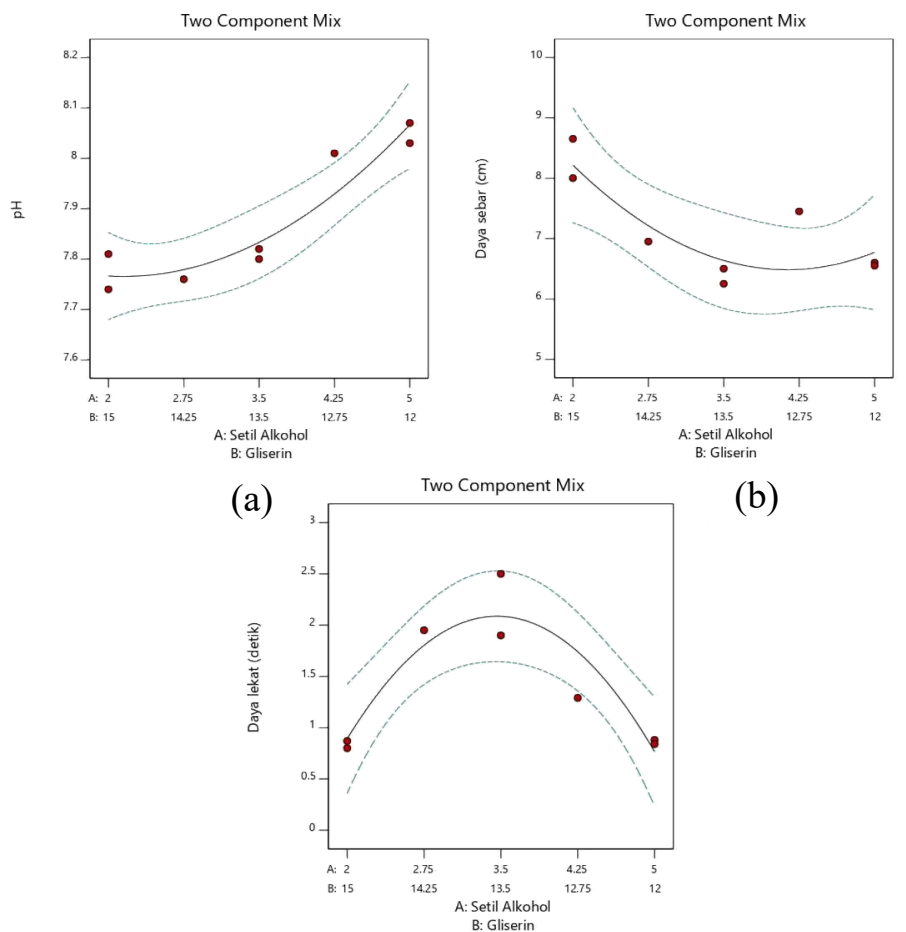

(b)

(c)

Gambar 2. Counter plot masing-masing respon (a) $\mathrm{pH}$, (b) daya sebar dan (c) daya lekat dalam optimasi dengan software design expert

Tabel 4. Komposisi dan Respon Formula Optimum Hasil Prediksi Software

\begin{tabular}{cccccc}
\hline \multicolumn{2}{c}{ Komposisi (\%) } & \multicolumn{3}{c}{ Respon } & Desirability \\
\cline { 1 - 4 } $\begin{array}{c}\text { Setil } \\
\text { alkohol (A) }\end{array}$ & Gliserin (B) & $\mathrm{pH}$ & $\begin{array}{c}\text { Daya sebar } \\
(\mathrm{cm})\end{array}$ & $\begin{array}{c}\text { Daya lekat } \\
(\text { detik })\end{array}$ & \\
\hline 3,93 & 13,07 & 7,88319 & 6,5 & 1,96449 & 1,000 \\
\hline
\end{tabular}

Tabel 5. Hasil Uji Organoleptis Sediaan Optimum Lotion

\begin{tabular}{cc}
\hline Parameter & Hasil \\
\hline Warna & Hijau kecoklatan \\
Bau & Bau khas daun jambu biji \\
Konsistensi & Kental \\
\hline
\end{tabular}

Tabel 6. Hasil Analisis Nilai Respon Prediksi dan Percobaan

\begin{tabular}{ccccc}
\hline Respon & Prediksi & Percobaan & $\begin{array}{c}\text { Signifikansi } \\
\text { 2-tailed }\end{array}$ & Kesimpulan \\
\hline $\mathrm{pH}$ & 7,883 & $7,942 \pm 0,037$ & 0,052 & Tidak berbeda \\
Daya sebar & 6,500 & $6,350 \pm 0,460$ & 0,561 & Tidak berbeda \\
Daya lekat & 1,964 & $0,975 \pm 0,310$ & 0,008 & Ada perbedaan \\
\hline
\end{tabular}

\section{PEMBAHASAN}

Pada penelitian ini dilakukan optimasi formula sediaan lotion ekstrak daun jambu biji (Psidium guajava L.) dengan menggunakan variasi konsentrasi dua faktor yaitu setil alkohol dan gliserin, dimana kedua bahan ini 
mempengaruhi parameter sifat fisik ( $\mathrm{pH}$, daya sebar, dan daya lekat). Untuk memvariasikan kedua bahan tersebut, terlebih dahulu ditentukan nilai Lower Limit dan Upper Limit dari masing-masing bahan. Nilai Lower Limit dan Upper Limit untuk setil alkohol yang berfungsi sebagai penstabil menurut Rowe et al. (2009) berkisar antara 2-5\%. Sedangkan untuk gliserin yang berfungsi sebagai humektan nilai Lower Limit dan Upper Limit yang digunakan berkisar antara 12-15\% (Lestari, 2019). Optimasi formula sediaan lotion ekstrak daun jambu biji ini dilakukan dengan menggunakan metode Simplex Lattice Design dan dianalisis menggunakan software Design Expert versi 11 dengan cara menginput data hasil uji respon $(\mathrm{pH}$, daya sebar dan daya lekat) 8 formula untuk mendapatkan formula optimum.

Nilai $\mathrm{pH}$ merupakan parameter yang dapat digunakan untuk melihat keamanan dari suatu sediaan. Apabila nilai $\mathrm{pH}$ sediaan lotion terlalu asam maka dapat menyebabkan terjadinya iritasi pada kulit sedangkan jika $\mathrm{pH}$ sediaan terlalu basa dapat menyebabkan kulit kering dan bersisik (Tranggono \& Fatimah, 2007; Dominica \& Dian, 2019). Syarat $\mathrm{pH}$ untuk sediaan topikal yang baik yaitu 4,5-8,0 (Mardikasari et al., 2017). Selain dari segi keamanan tujuan dilakukannya uji $\mathrm{pH}$ ini yaitu untuk melihat keamanan sediaan lotion. Jika $\mathrm{pH}$ terlalu rendah maka sediaan akan bersifat asam, ketika dioleskan ke kulit maka akan menyebabkan iritasi, sebaliknya $\mathrm{pH}$ sediaan yang tinggi akan menyebabkan kulit kering (Subaidah et al., 2020). Berdasarkan persamaan yang menggambarkan nilai respon $\mathrm{pH}$ (tabel 2) tersebut untuk masing-masing komponen yaitu setil alkohol dan gliserin menunjukkan respon yang positif terhadap $\mathrm{pH}$ sediaan lotion. Setil alkohol memberikan respon yang lebih tinggi yaitu $(+8,07)$ dalam meningkatkan $\mathrm{pH}$ sediaan. Menurut Rahmatika (2017) selain untuk mengetahui derajat keasaman, nilai $\mathrm{pH}$ juga menjadi parameter dalam menentukan stabilitas suatu sediaan sehingga dalam hal ini konsentrasi setil alkohol yang semakin tinggi dapat meningkatkan stabilitas dari suatu sediaan. Sedangkan untuk interaksi setil alkohol dan gliserin yang ditunjukkan oleh Contour plot (gambar 2) menghasilkan kurva yang melengkung ke atas menandakan adanya interaksi negatif dari kedua komponen sehingga campuran setil alkohol dan gliserin dapat menurunkan $\mathrm{pH}$ sediaan lotion ekstrak daun jambu biji.

Daya sebar merupakan parameter yang penting dalam memformulasikan suatu sediaan topikal. Tujuan dilakukannya pengukuran daya sebar ini adalah untuk mengetahui kemampuan penyebaran sediaan lotion ekstrak daun jambu biji (Psidium guajava L.) pada kulit setelah diaplikasikan sehingga dapat memenuhi syarat penyebaran yang berkisar $5-7 \mathrm{~cm}$ (Dominica \& Dian, 2019). Daya sebar juga dapat menggambarkan viskositas sediaan, semakin besar nilai daya sebar maka semakin rendah nilai viskositas sediaan tersebut (Deuschle et al., 2015) Respon daya sebar tersaji dalam tabel 2. Dari persamaan tersebut terlihat bahwa masing-masing komponen yaitu setil alkohol dan gliserin memberikan respon yang positif terhadap peningkatan daya sebar sediaan lotion. Respon tertinggi terdapat pada gliserin yaitu $(+8,22)$ dimana konsentrasi gliserin yang semakin besar dapat melunakkan sediaan (Saryanti \& Izzatun, 2017) dan sangat berpengaruh dalam menurunkan viskositas sediaan yang dapat diamati dimana semakin rendah viskositas maka daya sebarnya akan semakin besar (Haryanto, 2019). Viskositas ini juga dipengaruhi oleh konsentrasi dari setil alkohol, semakin rendah konsentrasi setil alkohol yang digunakan maka viskositasnya akan semakin kecil (Nining \& Radjab et al., 2019). Sedangkan untuk interaksi setil alkohol dan gliserin yang ditunjukkan oleh 
Contour plot (gambar 2) menghasilkan kurva yang melengkung ke atas menandakan adanya interaksi negatif dari kedua komponen sehingga campuran setil alkohol dan gliserin dapat menurunkan daya sebar sediaan lotion ekstrak daun jambu biji.

Respon daya lekat digunakan sebagai parameter untuk melihat kemampuan suatu sediaan topikal melekat pada kulit setelah diaplikasikan (Utari et al., 2019). Semakin lama waktu sediaan lotion melekat pada kulit maka semakin banyak pula zat aktif yang berdifusi ke dalam kulit sehingga semakin efektif penggunaannya (Jayadi, 2013). Syarat daya lekat yang baik untuk sediaan topikal menurut Azkiya et al. (2017) yaitu tidak kurang dari 4 detik. Berdasarkan persamaan respon daya lekat tersebut masing-masing komponen yaitu setil alkohol dan gliserin menunjukkan respon yang positif. Respon tertinggi dihasilkan oleh gliserin yaitu $(+0,8908)$. Konsentrasi gliserin yang semakin tinggi akan menyebabkan viskositas yang diberikan akan semakin rendah (Haryanto, 2019). Menurut Chomariyah et al. (2019), viskositas ini berbanding lurus dengan daya lekat suatu sediaan. Hal ini dapat disebabkan karena fungsi gliserin sebagai humektan mampu mengikat air sehingga dapat meningkatkan atau menurunkan ukuran unit molekul yang akan mempengaruhi viskositas sediaan (Sukmawati et al., 2013). Sedangkan untuk interaksi setil alkohol dan gliserin yang ditunjukkan oleh Contour plot menghasilkan kurva yang melengkung ke bawah menandakan adanya interaksi positif dari kedua komponen sehingga campuran setil alkohol dan gliserin dapat meningkatkan daya lekat sediaan lotion ekstrak daun jambu biji.

Data hasil prediksi Design Expert menghasilkan formula optimum dengan nilai desirability sebesar 1 seperti yang tertera pada tabel 4 . Nilai desirability yang mendekati 1 menunjukkan formula yang diharapkan, artinya semakin tinggi kesesuaian formula yang diperoleh untuk mencapai formula yang optimum (Ittiqo \& Abdul, 2018). Sebaliknya jika nilai desirability mendekati 0 menunjukkan formula yang tidak diharapkan (Santoso et al., 2018). Berdasarkan data hasil prediksi dan percobaan diperoleh nilai respon $\mathrm{pH}$ dan daya sebar dari prediksi software Design Expert Versi 11 menunjukkan hasil yang tidak berbeda secara signifikan dengan nilai respon $\mathrm{pH}$ dan daya sebar dari hasil percobaan. Hal ini ditunjukkan dengan adanya nilai p (signifikansi 2-tailed) $>0,05$ (Elcistia \& Abdul, 2018). Sedangkan untuk nilai respon daya lekat didapatkan hasil yang berbeda signifikan dengan nilai $\mathrm{p}<0,05$. Hal ini dapat oleh ketidaktepatan pada saat menentukan waktu pisah kedua kaca objek yang digunakan dalam melakukan uji daya lekat sehingga hasil yang diperoleh tidak sesuai.

\section{SIMPULAN}

Formula optimum sediaan lotion ekstrak daun jambu biji (Psidium guajava L.) diperoleh dengan konsentrasi setil alkohol 3,93\% dan gliserin 13,07\%. Sifat fisik sediaan lotion ekstrak daun jambu biji formula optimum yaitu lotion berwarna hijau kecoklatan, bau khas daun jambu biji, konsistensi kental, $\mathrm{pH}$ sebesar 7,94, daya sebar sebesar $6,35 \mathrm{~cm}$, dan daya lekat sebesar 0,97 detik. 


\section{REFERENSI}

Alissya, R. L., \& Maimunah, Y., 2008. Aktivitas antioksidan krim ekstrak sari tomat (Solanum Lycupersicum L.). Traditional Medicine Journal.,18(3):132-140.

Aulton, M.E., 2007. Pharmaceutics The Design and Manufacture of Medicines. Third Edition, Churcihill Livingstone Elsivier, Toronto: 175-177.

Azkiya, Z., Herda, A., \& Tyas, S.N., 2017. Evaluasi sifat fisik krim ekstrak jahe merah (Zingiber officinale Rosc. Var. Rubrum) sebagai anti nyeri. Journal of Current Pharmaceutical Sciences., 1(1):12-8.

Chomariyah, N., Farida, L.D., \& Sumi, W., 2019. Optimasi sediaan pelembab ekstrak kering kulit buah manggis (Garcinia mangostana) dengan kombinasi asam stearate dan trietanolamin sebagai emulgator. Journal of Pharmacy Science and Practice, 6(1): 16-24.

Deuschle, V.C.K.N., Deuschle, R.A.N., Bortoluzzi, M.R., \& Athayde, M.L., 2015. Physical chemistry evaluation of stability, spreadability, in vitro antioxidant, and photoprotective capacities of topical formulations containing Calendula officinalis L. leaf extract. Brazilian Journal of Pharmaceutical Sciences, 51(1):63-75.

Dominica, D., \& Dian, H., 2019. Formulasi dan evaluasi sediaan lotion dari ekstrak daun lengkeng (Dimocarpus Longan) sebagai antioksidan. Jurnal Farmasi dan Ilmu Kefarmasian Indonesia., 6(1):1-7.

Elcistia, R., \& Abdul, K.Z., 2018. Optimasi formula sediaan krim o/w kombinasi oksibenzon dan titanium dioksida serta uji aktivitas tabir suryanya secara in vivo. Majalah Farmasetika., 14(2):63-78.

Haryanto, T. J., 2019. Optimasi carbopol 940 dan gliserin pada gel antibakteri Staphylococcus aureus ekstrak etanol biji pepaya (Carica papaya L.) aplikasi design faktorial, Skripsi, Universitas Sanata Dharma, Yogyakarta.

Hendradi, E., Uswatun, C., Tiara, I., \& Fidela, F., 2013. Pengaruh gliserin dan propilenglikol terhadap karakteristik fisik, kimia dan spf sediaan krim tipe o/w ekstrak biji kakao (Thebroma cacao L.). PharmaScientia, 2(1):31-42.

Ittiqo, D.H., \& Abdul, R.W., 2018. Optimasi formula gel serbuk getah Ashitaba (Angelica keiskei Koidzumi) dan uji aktivitas terhadap lama penyembuhan luka eksisi pada kelinci. Pharmauho, 4(2):14-21.

Jayadi., 2013. Optimasi formula losion minyak atsiri buah adas (foeniculum vulgare) dengan kombinasi setil alkohol - natrium lauril sulfat terhadap sifat fisik dan aktivitas repelan pada nyamuk Anopheles aconitus betina, Naskah Publikasi. Universitas Muhammadiyah Surakarta, Surakarta.

Lestari, F. A., 2019. Optimasi formula dan evaluasi sediaan krim ekstrak daun katuk (Sauropus androgynous (L.) Merr.) variasi konsentrasi asam stearat, tea dan gliserin, Skripsi, Universitas Mataram, Mataram.

Mardikasari, S.A., Andi, N.T.A.M., Wa Ode, S.Z., \& Endeng, J., 2017, Formulasi dan uji stabilitas lotion dari ekstrak etanol daun jambu biji (Psidium guajava L.) sebagai antioksidan. Jurnal Farmasi Sains dan Kesehatan, 3(2):28-32.

Mulyani, T., Ariyani, H., Rahimah, \& Rahmi, S., 2018. Formulasi dan aktivitas antioksidan lotion ekstrak daun suruhan (Peperomia pellucida L.). Journal of Current Pharmaceutical Sciences, 2(1): 111-117.

Nining, N.S., \& Radjab, W.S., 2019, Stabilitas Fisik Krim M/A Ekstrak Buah Jambu Biji (Psidium guajava L.) Dengan Variasi Setil Alkohol Sebagai Stiffening Agent. Journal of Current Pharmaceutical Sciences, 2(2):142-148.

Rahmatika, A., 2017. Formulsi dan uji aktivitas antioksidan sediaan krim ekstrak etanol 70\% daun ashitaba (Angelica keiskei Koidz) dengan setil alkohol sebagai stiffening agent, Skripsi, UIN Syarif Hidayatullah, Jakarta.

Rowe, R. C., Sheskey, P. J., \& Quinn, M. E., 2009. Handbook of Pharmaceutical Excipients. Pharmaceutical Press, Minneapolis.

Sari, A, N., 2015, Antioksidan Alternative Untuk Menangkal Bahaya Radikal Bebas Pada Kulit, Universitas Islam Negri ArRaniry. Banda Aceh.

Saryanti, D., \& Izzatun, N. Z., 2017. Optimasi karbopol dan gliserol sebagai basis gel antiseptik tangan ekstrak etanol daun ceremai (Phyllantus Acidus (L.) Skeels) dengan metode simplex lattice design, Journal of Pharmaceutical Science and Clinical Research, 2:35-43.

Subaidah, W.A., Hajrin, W., \& Juliantoni, H., 2020. Formulasi dan evaluasi sifat fisik lotion ekstrak etanol daun kemuning (Murraya paiculata (L) Jack) dan daun lidah buaya (Aloe vera Linn). Sasambo Journal of Pharmacy, 1(1), 12-16.

Sukmawati, N.M.A., Arisanti, C.I.S., \& Wijayanti, N.P.A.D., 2013. Pengaruh Variasi Konsentrasi PVA, HPMC, dan Gliserin Terhadap Sifat Fisika Masker Wajah Gel Peel Off Ekstrak Etanol 96\% Kulit Buah Manggis (Garcinia mangostana L.), Bali, Universitas Udayana. 
Santoso, J., Rina, H., \& Mimiek, M., 2018. optimasi formula krim ekstrak poliherbal sebagai antibakteri dengan kombinasi gliserin, sorbitol dan propilrnglikol sebagai humektan. Jurnal Para Pemikir., 7(2):270-275.

Tranggono, R.I., \& Fatma, L., 2007. Buku Pegangan Ilmu Pengetahuan Kosmetik, PT. Gramedia Pustaka Utama, Jakarta: 11.

Utari, K.D.P., Unique, I.G.A.N.P., Aryani, N.W.G., Arisanti, C.I.S., \& Samirana, P.O., 2019. Optimasi formula krim ekstrak rimpang kunyit (curcuma domestica) dengan variasi konsentrasi setil alkohol sebagai agen pengental. Jurnal Farmasi Udayana., 7(2): 4044.

Vyas, N., Tailang, M., \& Gavatia, N.P., 2010, Antioxidant potential of Psidium guajava Linn. International Journal of Pharmatech Research, 2(1):417-419.

\section{UCAPAN TERIMA KASIH}

Ucapan terimakasih disampaikan kepada semua pihak yang telah membantu dan kepada dosen pembimbing yang telah memberikan arahan dan masukan sehingga penelitian ini dapat berjalan dengan lancar.

\section{KONTRIBUSI PENULIS}

Hardiyanti Dewi Azmi berperan dalam mengumpulkan data, interpretasi data dan membuat naskah. Yohanes Juliantoni dan Windah Anugrah Subaidah berperan dalam membimbing dan mengarahkan pembuatan konsep dan rancangan. Semua penulis berkontribusi dalam penelitian dan menyetujui versi akhir naskah.

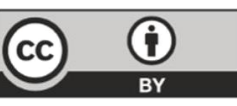

Akses Terbuka Artikel ini dilisensikan di bawah Creative Commons Lisensi Internasional Attribution 4.0, yang memungkinkan penggunaan, berbagi, adaptasi, distribusi, dan reproduksi dalam media atau format apa pun, selama Anda memberikan kredit yang sesuai kepada penulis asli dan sumbernya, memberikan tautan ke lisensi Creative Commons, dan menerangkan jika perubahan telah dilakukan. Gambar atau materi pihak ketiga lainnya dalam artikel ini termasuk dalam lisensi Creative Commons artikel, kecuali dinyatakan sebaliknya dalam batas kredit untuk materi tersebut. Jika materi tidak termasuk dalam lisensi Creative Commons artikel dan penggunaan yang Anda maksudkan tidak diizinkan oleh peraturan perundang-undangan atau melebihi penggunaan yang diizinkan, Anda harus mendapatkan izin langsung dari pemegang hak cipta. Untuk melihat salinan lisensi ini, kunjungi https://creativecommons.org/licenses/by/4.0/deed.id.

(C) The Author(s) 2021 